DOI 10.15393/j10.art.2018.3481

\author{
Валентина Васильевна Борисова \\ доктор филологических наук, профессор, \\ заведуюшая кафедрой русской титературь \\ Башкирского государственного педагогчческого \\ университета им. М. Акмулль \\ (Уба, Российская Федерация) \\ borisova@ufacom.ru
}

\title{
«ДЕЛО О КУМАНИНСКОМ НАС ДЕДСТВЕ» В ЖИЗНИ И ТВОРЧЕСТВЕ Ф. М. ДОСТОЕВСКОГО
}

Аннотация. В статье рассматривается так называемое «дело о куманинском наследстве», оставившее большой след в биографии и произведениях Ф. М. Достоевского. На фактическом материале, с привлечением архивных документов раскрывается огромное значение той помощи, которую на протяжении практически всей своей жизни писатель получал от богатых московских родственников Куманиных. Но доставшееся от них в денежном и имущественном выражении наследство оказалось для него «несчастным» (по точному определению В. М. Карепиной). Как видно из переписки Достоевского с братьями и сестрами, а также из архивных материалов, документов, представленных в ряде историко-биографических исследований, хроники судебного процесса по данному делу, он стал жертвой обстоятельств и интриг. Это подтверждается, в частности, историей с его долгом семейству Ивановых, отношения с которыми не выдержали испытания «куманинским делом» и привели в конечном счете к трагическому исходу - смерти писателя. В заключении статьи обозначены задачи дальнейшего рассмотрения «дела о куманинском наследстве» с нравственной, юридической точек зрения и в плане его отражения в творчестве писателя, в котором мотив «рокового наследства» имеет важное сюжетное и идейное значение.

Ключевые слова: Ф. М. Достоевский, «куманинское дело», биография, М. М. Достоевский, долг, А. Ф. Куманина, наследство, А. П. Иванов, судебный процесс, семья

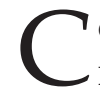

отрочества и до самой своей кончины Ф. М. Достоевский пользовался помощью богатой тетки со стороны матери Александры Федоровны Куманиной (1796-1871): «Покойница тетка имела огромное значение в нашей жизни, с детства...»․ Она была крестной матерью всех детей своей младшей сестры Марии Федоровны. Александра Федоровна вместе с мужем Александром Алексеевичем взяли на себя заботу о племянниках после смерти родителей. За будущего писателя они внесли плату при поступлении в Инженерное училище, продолжая поддерживать его материально долгие годы.

Многие факты подтверждают свидетельство дочери писателя Л. Ф. Достоевской: А. Ф. Куманина «покровительствовала своим племянникам и племянницам и особое предпочтение отдавала моему отцу, который был ее любимцем. Она одна из всей семьи оценила его и всегда была готова помочь ему» [Достоевская Л. Ф.: 21].

Как видно из писем, Достоевский часто обращался к обеспеченным московским родственникам, которые помогали ему и в 1840-е гг., еще до ареста, и во время ссылки, отправляя деньги в Семипалатинск. В феврале 1857 г.

(C) В. В. Борисова, 2018 
Федор Михайлович получил от них к свадьбе с М. Д. Исаевой 600 рублей. Материальная поддержка со стороны А. А. Куманина на протяжении более 20 лет была весьма существенной - видимо, поэтому, узнав о его смерти в 1863 г., Достоевский написал брату Михаилу Михайловичу:

«Дай Бог небесного царствия дяде. <...> Насчет наследства нам не надеюсь» $\left(28_{2}, 45\right)$.

Тем не менее свою долю - 3000 рублей пятипроцентными билетами он все же получил. Поскольку эти деньги быстро закончились, весь 1864 г. вместе с братом Достоевский строил планы получить займ на возобновление издания журнала «Эпоха» у А. Ф. Куманиной. Она выделила племяннику 10000 рублей в счет будущей части его наследства.

Однако после ее смерти в 1871 г. завещание в части недвижимого имущества и имения было оспорено Достоевскими по той причине, что они являлись единоутробными родственниками покойной в отличие от Владимира Дмитриевича и Сергея Дмитриевича Шеров, сыновей ее единокровной сестры Ольги Федоровны, родившейся во втором браке Федора Тимофеевича Нечаева с Ольгой Яковлевной Антиповой и бывшей замужем за Дмитрием Александровичем Шером. Двоюродные по крови братья Федора Михайловича тоже претендовали на наследство А. Ф. Куманиной (см. об этом: [Ильин: 548-559]). Начался долгий судебный процесс, отнявший у писателя много времени, сил и нервов. Оказалась права В. М. Карепина, признаваясь в письме к А. М. Достоевскому (28 мая 1873 г.): «...это наследство такое несчастное, что все перессорятся из-за него» [Литературное наследство: 432].

В затянувшемся «деле» приняли участие все сонаследники. Сестры и братья подозревали Федора Михайловича в корыстных интересах, полагая, что свою часть он давно и сполна получил. Действительно, расписку о получении денег в счет наследства Достоевский дал своей тетке еще в мае 1864 г. [Литературное наследство: 433].

Оправдываясь и опровергая «бесчисленные слухи и толки», возникшие среди родственников, Федор Михайлович писал 16 (28) декабря 1869 г. брату А. М. Достоевскому как душеприказчику А. Ф. Куманиной о том, что полученные от нее в 1864 г. 10000 рублей целиком ушли на уплату долгов М. М. Достоевского, поддержку его семейства и журнала «Эпоха», а после того, как «журнал лопнул», было выплачено долгов «еще до одиннадцати тысяч из своих денег» - «кончилось тем, что я и теперь еще 4000 должен по векселям за журнал и за долги брата...» $\left(29_{1}, 97\right)$.

Среди них был, например, долг М. М. Достоевского перед семейством А. П. Иванова (см. об этом: [Борисова, 2009: 46-51]). В апреле 1864 г., не надеясь получить деньги от А. Ф. Куманиной, Михаил Михайлович для поддержания журнала «Эпоха» взял у мужа сестры Веры взаймы сорок 
акций Ярославской железной дороги на 6000 рублей серебром, которые приносили годового доходу по восемь рублей каждая. А. П. Иванов дал акции в долг «из радушия и родственного участия» (см. письмо Ф. М. Достоевского к старшему брату от 23 апреля 1864 г. - 28, 93), хотя они предназначались для приданого его дочерям - Маше и Соне. Как писал Достоевский старшему брату, «процентами они платят за уроки на фортепьяно и одеваются <...>. Эти-то деньги он и хочет по совету с Верочкой предложить тебе» $\left(28_{2}, 93\right)$. Сам Федор Михайлович выступил посредником и поручителем за Михаила Михайловича, как это видно из его писем А. М. Достоевскому (23 апреля 1864 г.), С. А. Ивановой (8 (20) марта 1869 г. и 14 (26) декабря 1869 г.), Ивановым (1 (13) февраля 1868 г.) $)^{2}$.

Акции Михаил Михайлович получил и заложил за 5000 рублей․․ За ними он ездил в Москву уже после отъезда Федора Михайловича в Петербург (29, 402). Вернуть их Иванову Михаил Михайлович не успел, так как скоропостижно скончался 10 июля 1864 г. Через год Александр Павлович обратился к вдове Эмилии Федоровне Достоевской с просьбой вернуть акции, взывая к ее «чести, совести, долгу» ${ }^{4}$. Но та ответила отказом, отослав А. П. Иванова к Федору Михайловичу. По ее словам, именно он заложил акции. У нее же самой «решительно» «ничего нет»: ни денег, ни акций ${ }^{5}$. С ее стороны это был обман и клевета на Федора Михайловича, которого многие годы тяготил долг покойного Михаила Михайловича перед Ивановыми, взятый им на себя.

В своей братской жертве писатель оказался обманут. 25 марта 1866 г. Эмилия Федоровна выдала своему сыну Федору Михайловичу Достоевскому-младшему доверенность на выкуп у купца 1-й гильдии Б. М. Райха оставшихся в наследство от М. М. Достоевского и заложенных им акций Ярославской железной дороги ${ }^{6}$ (см. Приложение). Б. М. Райх, в свою очередь, выдал 7 апреля 1866 г. Э. Ф. Достоевской расписку в том, что он «по заложенным сорока акциям Московской Ярославской железной дороги три тысячи рублей серебром с процентами сполна получил» от нее и поданное им в Санкт-Петербургскую управу дело ко взысканию прекращается (см. Приложение).

И. А. Битюгова, комментируя этот факт, отметила: «Денежная помощь для выкупа акций, вероятно, была оказана Д<остоевск>им» [Летопись: 62], что вполне возможно. Векселей к взысканию предъявлялось писателю в ту пору много: «...у меня бессчетное число дел с кредиторами» $\left(28_{2}, 148\right)$; «с меня так и рвут!» $\left(28_{2}, 157\right),-$ признавался он в отчаянии Д. И. Достоевской и А. Е. Врангелю.

Судя по всему, писатель не знал о том, что Эмилия Федоровна уже выкупила акции А. П. Иванова, которые она должна была вернуть его семейству. Ее лживость очевидна: весной 1866 г. акции были в ее руках, она получала с них проценты и, тем не менее, продолжала требовать денежную 
помощь от Федора Михайловича, задыхавшегося от «наследства», оставленного братом, и не ведавшего о том, что произошло с акциями.

Это ясно из его письма осиротевшим В. М., С. А. и М. А. Ивановым, посланного 1 (13) февраля 1868 г.: «...после смерти Миши летом, в Люблине, кажется, Александр Павлович, узнав от меня же о получении моем от тетки 10000 руб. и о том, что я принимаюсь продолжать журнал, напомнил мне о моем отчасти - поручительстве, данном ему на слово в уплате ему за брата, и просил иметь непременно в виду, при первом успехе журнала, эту уплату. Я обещал твердо, имея полнейшее намерение исполнить» $\left(28_{2}, 255\right)$.

В Люблине Достоевский был летом 1866 г. Получается, что ни А. П. Иванов, ни сам писатель не знали тогда об уже выкупленных Эмилией Федоровной акциях, и зимой 1868 г. Федор Михайлович все еще считал их своим долгом. Тяготясь и терзаясь им, он пишет Ивановым:

«Сейчас я ничего не имею, но в этот общий час, когда нас связывает общая великая печаль, объявляю тебе, Верочка, и вам, Сонечка и Машенька, и всем: что ничего святее и крепче не будет для меня теперь отдачи вам этого долга брата Миши за акиии! Когда это будет, когда я в состоянии буду - не знаю <...>. Но все-таки когда-нибудь от меня возвращения этих денег ожидать вам можно. Это я обязанностью счел заявить» $\left(28_{2}, 256\right)$.

Сам писатель в это время находился в жесточайшем материальном и душевном состоянии. Уехав за границу, он не мог не думать о долгах, за которые его продолжала ругать вдова брата: «...у Эм<илии> Федоровны меня бранят на чем свет стоит» (письмо к А. Н. Майкову от 2 (14) марта 1868 г. $\left.28_{2}, 272\right)$. В отчаянии писатель признавался: «Вместо того, чтоб бросить <им> (семейству Эмилии Федоровны. - В. Б.) эти 10 000, да потом до двенадцати (если не более) тысяч уплатить кредиторам, да еще и теперь быть должным, - лучше бы я Вам отдал теперь 5 тысяч, которые покойный Александр Павлович отдал брату за три месяиа до его смерти» (письмо к С. А. Ивановой от 8 (20) марта 1869 г. - 29, 29).

Именно об этом долге Федор Михайлович упоминает чаще всего. В письме Ивановым от 1 (13) февраля 1868 г., посланном сразу после получения им известия о кончине Александра Павловича, он подчеркивает: «Теперь еще одно для меня главное дело» (курсив мой. - В. Б.), - и повторяет свое обязательство уплатить долг покойного брата $\left(28_{2}, 255\right)$.

Конечно, это обстоятельство не способствовало сохранению сердечных отношений Федора Михайловича с Ивановыми. Разрушилась даже его идеальная дружба-любовь к племяннице Соне; судя по всему, родственные чувства Достоевских не выдержали испытания «куманинским делом».

Замученный безденежьем, долгами, Федор Михайлович с жаром ухватился за возможность поправить свои дела благодаря пересмотру завещания богатой тетушки. 7 августа 1869 г. А. Н. Майков написал Достоевскому 
письмо с сообщением о смерти А. Ф. Куманиной и о том, что «осталось завещание, отдающее 40,000 в пользу какого-то монастыря» ${ }^{7}$. Слух о смерти, как обнаружилось впоследствии, оказался ложным, но Федор Михайлович успел отправить письма В. И. Веселовскому (14 (26) августа) ${ }^{8}$, адвокату и опекуну А. Ф. Куманиной, и С. А. Ивановой (29 августа (10 сентября) ${ }^{9}$, обратившись к ним с рядом важных для себя вопросов и соображений по делу о наследстве. Любимая племянница ответила первой, но ее мнение о возможности оспорить завещание А. Ф. Куманиной было резко отрицательным: «...цель не оправдывает средства» $\left(29_{1}, 90\right)$. Раздражением и подозрительностью отреагировал на это и брат Андрей Михайлович. Всполошилась вся московская родня, поскольку Сонечка рассказала родным о запросе писателя, хотя он настоятельно просил ее сохранить тайну до полного выяснения всех обстоятельств: «...дело секретное, и потому умоляю, чтоб оно не вышло из Вашего дома никуда и ни к кому...» (письмо Ф. М. Достоевского к С. А. Ивановой от 29 августа (10 сентября) 1869 г. - 29, 59).

Так Федор Михайлович оказался в атмосфере недоверия, даже вражды с братьями и сестрами. Младшая сестра А. М. Голеновская-Шевякова трижды затевала судебный процесс против него, не веря в искренние намерения брата защитить интересы сестер. Совсем испортились отношения с Ивановыми. 10 декабря 1875 г. писатель с обидой сообщает брату Андрею, что «верочкины дети» Виктор и Алексей, учась в Петербурге уже несколько лет, ни разу у него не были $\left(29_{2}, 66\right)$. О полном разрыве с любимой племянницей из-за куманинского наследства свидетельствует обращение Достоевского из Эмса к Е. П. Ивановой (5 (17) июня 1875 г.), которую он попросил передать письмо Соне:

«Софья Александровна, вместе с другими, слухам поддалась и меня обвинила. Бог с нею <...>. Узнав о ее мнении, я был очень печален...» $\left(29_{2}, 37\right)$.

В ответ (20 июня 1875 г.) Е. П. Иванова написала: «Относительно письма Вашего к Соне, скажу только, что я никогда не желала бы получить подобное от человека, которого я привыкла любить и которому верила», добавив, «в Вас она никогда не сомневалась до нынешнего года» ${ }^{10}$.

Осенью 1877 г., видимо, пытаясь возродить родственные отношения, Достоевский отправляет письмо В. М. Ивановой с обещанием выслать ей деньги. В ответном письме сестра благодарит Федора Михайловича и Анну Григорьевну:

«Спасибо, спасибо Вам, мои милые, что хотите помочь мне. Вы сами и не ведаете, сколько Вы мне делаете добра, мне и моим детям. Насчет же наследства, видит Бог, что я и забыла о нем. Для меня оно казалось всегда самым несбыточным делом, и потому, может быть, я переношу потерю его гораздо легче многих...»" ${ }^{11}$. 
Казалось бы, сердечные и родственные связи восстановились, однако в 1880 г. писателя поздравило с днем рождения только семейство А. М. Достоевского.

Итоговым в семейных разбирательствах стал роковой визит сестры Веры 26 января 1881 г., который закончился бурной ссорой из-за куманинского наследства: Федор Михайлович не захотел отказаться от своей доли в рязанском имении, мечтая оставить детям «лес» и «землю» как главные ценности. Анна Григорьевна записала его последние слова:

«Любил лес, пусть все продают, а я не продам, из принципа не продам, чтоб не безлесить Россию. Пусть мне выделят лесом, и я его стану растить и к совершеннолетию детей он будет большим» ${ }^{12}$.

Сакральным было отношение Достоевского и к земле:

«Земля всё <...> у всех должна быть земля, и дети должны родиться на земле» $(23,95)$.

После разговора с сестрой у Достоевского хлынула кровь из горла - через два дня писателя не стало. Вдова Анна Григорьевна сохранила его слова после причащения:

«[Я причастился, исповедался, а все-таки не могу равнодушно подумать о сестрах]. Какие они несправедливые» ${ }^{13}$.

После кончины Федора Михайловича его часть наследства Анна Григорьевна передала В. М. Ивановой. Это отмечено в письме В. М. Ивановой к Н. М. Достоевскому: «...Анна Григорьевна отдала мне свою часть по наследству...»" ${ }^{14}$. Так закончилось для Достоевского «куманинское дело», оставившее существенный след в судьбе писателя. Несмотря на имеющиеся историко-биографические изыскания по этой теме (см.: [Сараскина], [Тихомиров: 219-220], [Якубович], [Dostoevsky in Context], [Frank]), в полной мере оно еще не рассмотрено, в нем есть «темные места», нуждающиеся в прояснении. Чтобы восстановить всю хронику судебного процесса, предстоит разобраться в справедливости притязаний всех наследников с нравственной и юридической точек зрения, соотнести денежные расчеты писателя, связанные с изданием журналов «Время» и «Эпоха» (НИОР РГБ. Ф. 93.І.3.23 и др.), с приходно-расходными журналами за 1861-1865 гг. (НИОР РГБ. Ф. 93.І.3.21, Ф. 93.І.3.22), изучить материалы архива Достоевского не только в НИОР РГБ, но и в РГАЛИ ${ }^{15}$, РО ИРЛИ (переписка Куманиных, А. М. Достоевского - ф. 56), письма, имеющие отношение к «куманинскому делу» ${ }^{16}$, и другие документы.

И самое главное: «куманинское дело», сыгравшее важную роль в судьбе Достоевского, заслуживает дальнейшего рассмотрения с точки зрения его 
отражения в произведениях писателя, в которых мотив «рокового наследства» имеет большое сюжетное и идейное значение.

Это в особенности касается его послекаторжного творчества (прежде всего «Записок из Подполья», «Игрока», «Униженных и оскорбленных», всего романного «пятикнижия»), в котором перипетии «дела о куманинском наследстве» преломились в структуре образов персонажей и фабуле.

\section{ПРИМЕЧАНИЯ}

1 Достоевский Ф. М. Письмо к С. А. Ивановой (1871 г.) // Достоевский Ф. М. Полн. собр. соч.: в 30 т. Л.: Наука, 1986. Т. 29. Кн. 1. С. 209. Далее ссылки на это издание приводятся в тексте статьи с указанием тома, книги (нижний индекс), страницы в круглых скобках.

2 См.: $\left(28_{2}, 92-93\right),\left(29_{1}, 23-28\right),\left(28_{2}, 253-256\right)$.

3 См. письма Ф. М. Достоевского к М. М. Достоевскому от 23 апреля 1864 г. $\left(28_{2}, 92-93\right)$ и А. М. Достоевскому от 29 июля 1864 г. (28, 94-96).

4 См. письмо Э. Ф. Достоевской к А. П. Иванову (1865 г.): [Литературное наследство: 404].

5 Там же: [Литературное наследство: 405].

6 Документы о залоге акций Ярославской железной дороги Э. Ф. Достоевской купцу Б. Райху // НИОР РГБ. Ф. 93.III.8.23.

Майков А. Н. Письмо к Ф. М. Достоевскому. От 7 августа 1869 г. // НИОР РГБ. Ф. 93.ІІ.6.43. Л. 6.

См.: $\left(29_{1}, 46-47\right)$.

См.: $\left(29_{1}, 55-60\right)$.

10 Иванова Е. П. Письмо к Ф. М. Достоевскому. От 20 июня 1875 г. // РО ИРЛИ. Р. І. Оп. 6. № 172 . Л. 1-1 об.

11 Иванова В. М. Письмо к Ф. М. и А. Г. Достоевским (1877 г.) // РО ИРЛИ. Ф. 100. № 29725. Л. 4 об.

12 Достоевская А. Г. Записная книжка 1881 г. См.: [Ф. М. Достоевский в забытых и неизвестных воспоминаниях современников: 281].

13 Текст, заключенный в квадратные скобки, записан стенографически и расшифрован Ц. М. Пошеманской. См: [Ф. М. Достоевский в забытых и неизвестных воспоминаниях современников: 281].

14 Иванова В. М. Письмо к Н. М. Достоевскому. Б. д. // НИОР РГБ. Ф. 93.III.12.59. Л. 8.

15 В частности, заслуживают внимания следующие архивные единицы РГАЛИ: 1) Документальные материалы по делу о куманинском наследстве - проекты доверенностей, счета, выписи из актовых книг, копии соглашений между наследниками (Ф. 212.1.121); 2) Дело о получении Ф. М. Достоевским куманинского наследства (машинописные копии - Ф. 212.3.1); 3) Проекты и копии доверенностей, выданных наследниками Ф. М. Достоевского Б. Б. Полякову на ведение дел по куманинскому наследству (Ф. 212.4.1, внутр. опись к ед. хр. 121) и др.

16 Напр., письма Ф. М. Достоевского к П. П. Казанскому (РГАЛИ. Ф. 212.1.39), к В. В. Шеру (РГАЛИ. Ф. 212.1.51), письма к Ф. М. Достоевскому Б. Б. Полякова (РГАЛИ. Ф. 212.1.89), письмо к А. Г. Достоевской Е. В. Корша по делу о куманинском наследстве (РГАЛИ. Ф. 212.1.194) и мн. др. 


\section{СПИСОК ЛИТЕРАТУРЫ}

1. Борисова В. В. «Долг чести» Ф. М. Достоевского // Достоевский и современность. Материалы XXIII Международных Старорусских чтений 2008 года. - Великий Новгород, 2009. - C. 46-51.

2. Борисова В. В. «...не могу заплатить самых святых долгов» // II Международный симпозиум «Русская словесность в мировом культурном контексте»: избранные доклады и тезисы. - Москва, 2008. - С. 270-276.

3. [Достоевская Л. Ф.] Достоевский в изображении его дочери Л. Достоевской / пер. с нем. Л. Я. Круковской, под ред. и с предисл. А. Г. Горнфельда. - М.; Петроград: Государственное издательство, 1922. - 105 с.

4. Достоевский Ф. М. Достоевская А. Г. Переписка. - М.: Наука, 1979. - 483 с.

5. Ильин Н. Достоевский в споре за куманинское наследство // Звенья. Т. IX. - М.; Л., 1951. - С. 548-559.

6. Летопись жизни и творчества Ф. М. Достоевского: в 3 т. - СПб.: Академический проект, 1994. - Т. 2: 1865-1874. - 587 с.

7. Сараскина Л. И. Система всегдашнего долга // Фёдор Достоевский. Одоление Демонов. - М.: Согласие, 1998. - С. 7-12.

8. Тихомиров Б. Н. «Лазарь! Гряди вон». Роман Ф. М. Достоевского «Преступление и наказание» в современном прочтении. Книга-комментарий. - 2-е изд. - СПб.: Серебряный век, 2016. - 555 с.

9. Ф. М. Достоевский в забытых и неизвестных воспоминаниях современников / вступ. ст., подгот. текста и примеч. С. В. Белова. - СПб.: «Андреев и сыновья», 1993. - 332 с.

10. Ф. М. Достоевский. Новые материалы и исследования. - Москва : Наука, 1973. 792 с. - (Серия «Литературное наследство» ; Т. 86).

11. Якубович И. Д. Неизвестные деловые бумаги Достоевского // Достоевский. Материалы и исследования. - Л.: Наука, 1987. — Т. 7. - С. 261-270.

12. Dostoevsky in Context / ed. by Deborah A. Martinsen, Olga Maiorova. - Cambridge: Cambridge University Press, 2016. - 351 p.

13. Frank Joseph. Dostoevsky: A Writer in His Time. - Princeton: Princeton University Press, 2009. -984 p. 


\title{
ПРИЛОЖЕНИЕ
}

\author{
$<\mathrm{I}>$
}

\section{<Доверенность Э. Ф. Достоевской на получение акций Ф. М. Достоевскому (младшему)>}

Симь довпряю сыну моему Дворянину Өедору Достоевскому получить сь

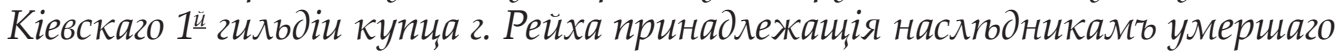
отставнаго Инженерь подпоручика Михаила, Достоевскаго, надь илпніемь ${ }^{1}$ которыхь я состою опекуншей, 40 акцій Московско-Ярославской желпзной дороги сь купонами 1865 года и уплатить слюдующія означенному купиу Рейху деньги по закладной. С. Петербургъ 25 Марта 1866 года.

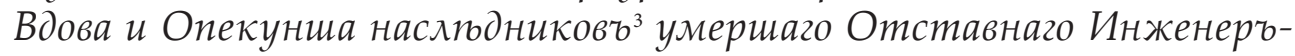
Подпоручика Михаиль Михаиловича Достоевскаго. Эмилія Достоевская

1866 года Марта 25 дня подпись руки вдовы Инженерь-Подпоручика Эмиліи Достоевской свидютельствую Васильевской Части 3 квартала.

Надзиратель <Далее подпись не разборчива.> <л. 7>

Источник текста: НИОР РГБ. Ф. 93.ІІІ.8.23. Л. 7.

Публикуется впервые.

$$
<\text { II }>
$$

\section{$<$ Расписка Б. Райха в получении денег от Э. Ф. Достоевской>}

1866 года Апрпляч 7о дня. Я нижеподписавшійся симь свидютельствую

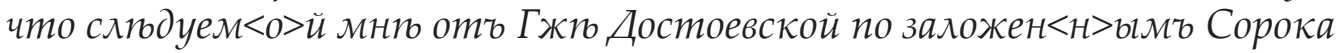
Акціялиь Московской Ярославской Желпзной дороги три тьсячи рублей серебромь съ процентали сполна получиль, и затпюмь взысканіе подан <н>ой мной въ Ст Петербургской Управы благочиній по сему дюлу прекращается7. Купецъь Борисъ Райхъ<.>< > 9>

Источник текста: НИОР РГБ. Ф. 93.III.8.23. Л. 9.

Публикуется впервые.

Подготовлено к публикации И. С. Андриановой, Е. Н. Вяль

\footnotetext{
${ }^{1}$ В рукописи ошибочно: именіемъ

${ }^{2}$ В рукописи ошибочно: железной

${ }^{3}$ В рукописи описка: насльниковь

${ }^{4}$ В рукописи ошибочно: Апреля

${ }^{5}$ В рукописи ошибочно: Железной

${ }^{6}$ В рукописи: съ процентамы

${ }^{7}$ В рукописи ошибочно: прекращаеться
} 


\title{
Valentina V. Borisova
}

\author{
Ph.D., Professor, \\ Head of the Russian Literature Department of \\ M. Akmullah Bashkir State Pedagogical University \\ (Ufa, Russian Federation) \\ borisova@ufacom.ru
}

\section{"THE KUMANIN HERITAGE CASE" IN LIFE AND WORKS OF F. M. DOSTOEVSKY}

\begin{abstract}
The article reviews the so called "Kumanin heritage case" which left a significant mark in biography and works of F. M. Dostoevsky. The "great importance" of the help that the writer had been receiving from wealthy Moscow relatives Kumanins throughout almost all his life is disclosed on the basis of nonficional materials. But monetary and estate heritage turned out to be "unlucky" for him, as V. M. Karepina pointed it out. As it resulted from Dostoevsky's correspondence with his brothers and sisters, the archival materials, documents presented in a number of historical and biographical researches as well as from the court records with regard to that case, he became a victim of circumstances and intrigues. This viewpoint that is confirmed, in particular, by the story of his debt to the Ivanovs. Their relations failed to stand against the Kumanin "case" and led to a tragic outcome - death of the writer. In conclusion the article specifies the issues for further studying of the "the Kumanin heritage case" from the moral and legal points of view and in terms of its reflection in writer's works, in which the motif of the "fateful heritage" has an important narrative and ideological meaning.
\end{abstract}

Keywords: F. M. Dostoevsky, "the Kumanin case”, biography, M. M. Dostoevsky, debt, A. F. Kumanina, heritage, A. P. Ivanov, trial, family

\section{REFERENCES}

1. Borisova V. V. “Debt of Honor” by F. M. Dostoevsky. In: Dostoevskiy i sovremennost'. Materialy XXIII Mezhdunarodnykh Starorusskikh chteniy 2008 goda [Dostoevsky and Modernity. Proceedings of the 23th International Staraya Russa Conference of 2008]. Novgorod the Great, 2009, pp. 46-51. (In Russ.)

2. Borisova V. V. «...I Can Not Pay the Most Holy Debts». In: II Mezhdunarodnyy simpozium «Russkaya slovesnost' $v$ mirovom kul'turnom kontekste»: izbrannye doklady i tezisy [Second International Symposium "Russian Literature in the World Cultural Context": Selected Reports and Abstracts]. Moscow, 2008, pp. 270-276. (In Russ.)

3. Dostoevskaya L. F. Dostoevskiy v izobrazhenii ego docheri L. Dostoevskoy [Dostoevsky as Figured by His Daughter L. Dostoevskaya]. Moscow, Petrograd, Gosudarstvennoe izdatel'stvo Publ., 1922. 105 p. (In Russ.)

4. Dostoevskiy F. M. Dostoevskaya A. G. Perepiska [Dostoevsky F. M. Dostoevskaya A. G. The Correspondence]. Moscow, Nauka Publ., 1979. 483 p. (In Russ.)

5. Il'in N. Dostoevsky in the Dispute for the Kumanin Heritage. In: Zven'ya. Moscow, Leningrad, 1951, vol. 9, pp. 548-559. (In Russ.)

6. Letopis' zhizni i tvorchestva F. M. Dostoevskogo: $v 3$ tomakh [The Chronicle of Dostoevsky's Life and Works: in 3 Vols]. St. Petersburg, Akademicheskiy proekt Publ., 1994, vol. 2: 1865-1874. 587 p. (In Russ.)

7. Saraskina L. I. System of Permanent Debt. In: Fedor Dostoevskiy. Odolenie Demonov [Fedor Dostoevsky. Overcoming of Demons]. Moscow, Soglasie Publ., 1998, pp. 7-12. (In Russ.) 
8. Tikhomirov B. N. «Lazar'! Gryadi von». Roman F. M. Dostoevskogo «Prestuplenie i nakazanie» v sovremennom prochtenii. Kniga-kommentariy ["Lazarus! Ridge Over There”. Dostoevsky's Novel "Crime and Punishment" in Modern Interpretation: The Commentary]. St. Petersburg, Serebryanyy vek Publ., 2016. 555 p. (In Russ.)

9. F. M. Dostoevskiy v zabytykh i neizvestnykh vospominaniyakh sovremennikov [F. M. Dostoevsky in the Forgotten and Unknown Memories of His Contemporaries]. St. Petersburg, "Andreev i synov'ya” Publ., 1993. 332 p. (In Russ.)

10. Fedor Dostoevskiy. Novye Materialy i issledovaniya [Fedor Dostoevsky. New Materials and Studies]. Moscow, Nauka Publ., 1973. 586 p. (Ser. "Literary Heritage”; vol. 86) (In Russ.)

11. Yakubovich I. D. Unknown Business Papers of Dostoevsky. In: Dostoevskiy. Materialy i issledovaniya [Dostoevsky. Materials and Researches]. Leningrad, Nauka Publ., 1987, vol. 7, pp. 261-270. (In Russ.)

12. Dostoevsky in Context. Edited by Deborah A. Martinsen, Olga Maiorova. Cambridge, Cambridge University Press Publ., 2016. 351 p. (In English)

13. Frank Joseph. Dostoevsky: A Writer in His Time. Princeton, Princeton University Press Publ., 2009. 984 p. (In English)

Received: February 25, 2018 